\title{
RASGOS Y MACROTENDENCIAS DE LA EDUCACIÓN SUPERIOR
}
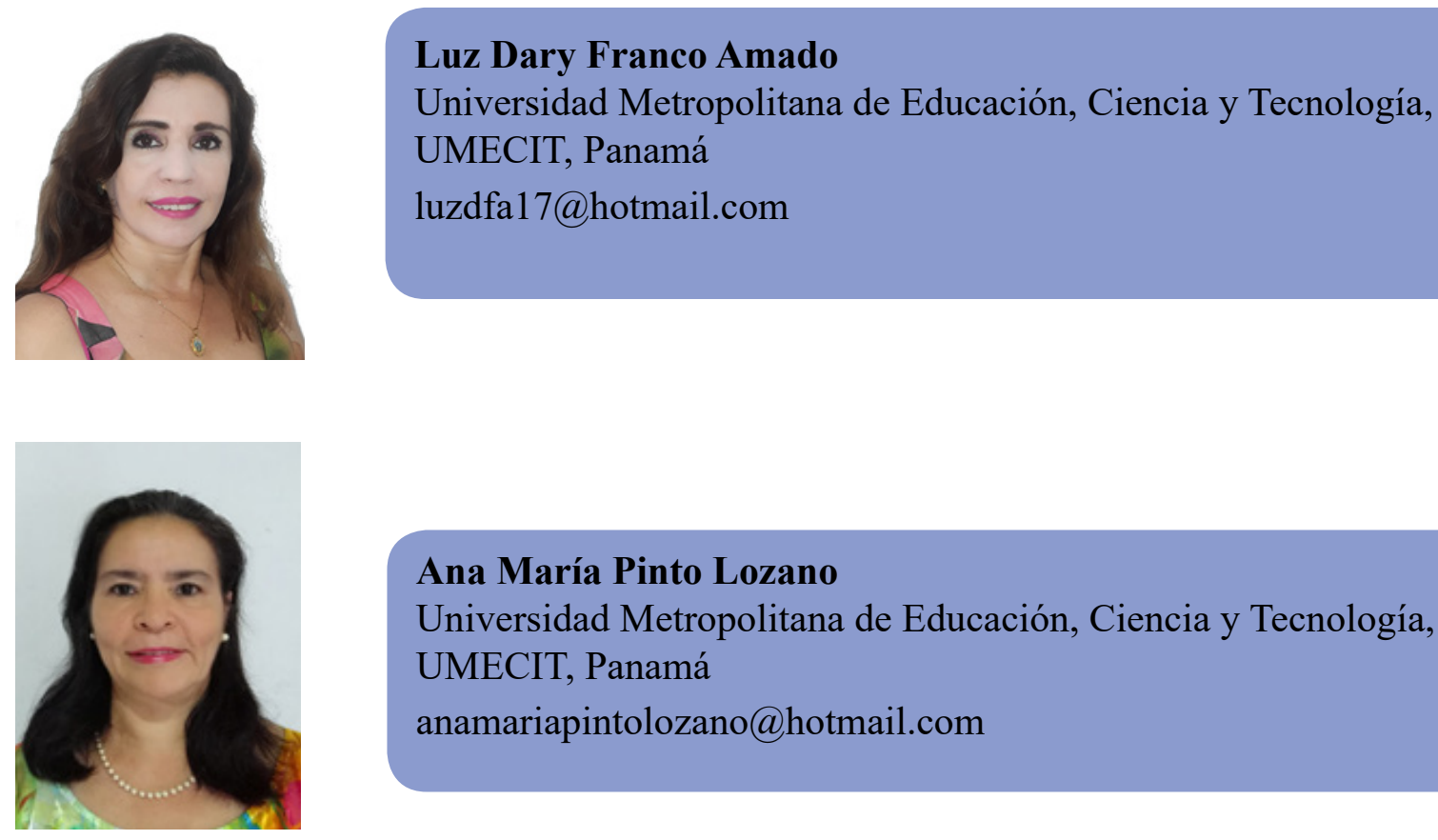

\section{Ana María Pinto Lozano \\ Universidad Metropolitana de Educación, Ciencia y Tecnología, UMECIT, Panamá \\ anamariapintolozano@hotmail.com}

"La educación es la clave para dar a cada niño una vida mejor y constituye el cimiento de todas las sociedades sólidas.”

Anthony Lake, Director Ejecutivo del UNICEF

\section{RESUMEN}

La Educación Superior considerada el motor de progreso en la sociedad requiere tener un espacio privilegiado en la reflexión de todos los campos de la academia; en razón a dar cumplimiento a este espacio de revisión y acercamiento, se recurre inicialmente a realizar la retrospectiva de la educación a nivel mundial y nacional, particularmente Colombia, como el eje articulador de épocas históricas con rasgos sociales, políticos y culturales predominantes que inciden en la intencionalidad y misión de la academia a nivel superior; esta retrospectiva comprende desde década de los 90 hasta la fecha. Seguidamente, se realiza un acercamiento a la diacronía de la ES con el objeto de evidenciar los rasgos y macro tendencias que se mantienen o han evolucionado desde y para su posicionamiento a nivel local, regional y mundial; para finalizar se presenta la concepción de la Responsabilidad social euleriana de la ES que transversaliza los procesos administrativos, académicos y pedagógicos de la educación.

Palabras clave: educación superior, macro tendencias, diacronía, internacionalización, eulerización. 


\title{
TRAITS AND MACROTRENDS OF HIGHER EDUCATION
}

\begin{abstract}
Higher Education (HE) is considered the engine of progress in society requires having a privileged space in the reflection of all fields of the academy; In order to comply with this space of revision and approach, we initially turn to the retrospective of education on a global and national level, particularly in Colombia, as the articulating axis of historical eras with predominant social, political and cultural features that affect the intentionality and mission of the academy at a higher level; this retrospective comprises from decade of the 90 to the date. Next, an approach to the diachrony of the HE is carried out in order to demonstrate the features and macro tendencies that are maintained or have evolved from and for its positioning at the local, regional and global level; Finally, the conception of the Eulerian social responsibility of the HE is presented, which mainstreams the administrative, academic and pedagogical processes of education.
\end{abstract}

Keywords: higher education, macro trends, diachrony, internationalization, eulerization.

\section{INTRODUCCIÓN}

La sociedad del conocimiento en su interés por otorgar el protagonismo que requiere la Educación Superior para alcanzar el objetivo de desarrollo sostenible número 4 "Garantizar una educación inclusiva y equitativa de calidad y promover oportunidades de aprendizaje permanente para todos" (UNESCO,2015), ha planteado principios elementales que deben ser acogidos de manera directa por los organismos y gobiernos internacionales, regionales y nacionales, a través de políticas y criterios que favorezcan su ejecución, control y seguimiento. Con respecto a este interés mundial se identifican y visibilizan históricamente macrotendencias como: calidad y pertinencia, prioridad en educación; educación para todos (EPT), factor humanista en la educación; educación y sostenibilidad, fusión necesaria; investigación y educación, factores prosociales; interculturalismo e internacionalización, nueva dialógica en la escuela y empleabilidad y emprendimiento, elementos visionarios de la educación superior. 
Posteriormente, en la diacronía de la educación superior se esbozan sus fundamentos tradicionales y su devenir histórico hasta su nueva visión holistica y humanista que incide en la transformación social de los pueblos.

Como colofón se presenta la propuesta de la Responsabilidad Social Euleriana de las 3E: educabilidad, empleabilidad y emprendimiento, como meta central de la Educación Superior. La educabilidad, en torno a la cual giran elementos como: la inclusión, la cobertura, la accesibilidad, la permanencia, la promoción y la calidad. El segundo componente de este proceso, es la empleabilidad, como la responsabilidad social de la ES, la cual convoca: financiamiento, humanismo, movilidad, sistemas de registro y acreditación, oferta y demanda laboral, competencias y profesionalización. En la escala más elevada, se ubica el emprendimiento, como la relación directa entre educación, economía y productividad, que generan riqueza, bienestar y empleo, impulsadores del desarrollo, en la cual se hace presente la internacionalización, interculturalismo y sostenibilidad. Se espera que esta propuesta sea el punto de partida para que la sociedad del conocimiento, genere los espacios para repensar, replantear y complementar este proceso de la Responsabilidad Social Euleriana de las 3E.

\section{Retrospectiva de la educación a nivel mundial y nacional (Colombia).}

En la revisión del fundamento normativo seleccionado, se realiza una lectura comparativa de cada uno de los referentes, dando prioridad a conceptos, términos y macro tendencias evidenciadas, a saber: calidad, pertinencia, inclusión y educación para todos (EPT), educación a lo largo de la vida, sostenibilidad, humanismo, investigación, financiamiento, emprendimiento, empleabilidad, interculturalismo e internacionalización como principios o ejes orientadores.

\section{Calidad y Pertinencia: prioridad en educación}

La pertinencia del servicio educativo, se ha planteado desde la década de los 90, como un principio orientador, porque si se presta un servicio de calidad, éste debe contribuir a resolver situaciones difíciles o de riesgo en la sociedad, por lo tanto, estos dos conceptos tienen una relación de complementariedad, es decir; Si se ofrece un servicio educativo de calidad este a su vez debe ser pertinente, entendido según lo expresado en La Conferencia Mundial sobre la Educación Superior para el siglo XXI. CMSE. (UNESC1998) como: “...en función de la adecuación entre lo que la sociedad espera de las instituciones y lo que éstas hacen”. (p.30). 
Teniendo en cuenta lo anterior surge el interrogante: ¿Qué se requiere para ofrecer calidad y pertinencia educativa? necesariamente, partir del contexto institucional y proyectarlo hacia espacios cada vez más amplios: como lo local, regional e internacional, para identificar los rasgos culturales, sociales y ambientales que requieren la intervención del sector educativo y direccionar todos los esfuerzos para cumplir con la Responsabilidad Social (RS), que no es más que la capacidad de sensibilización y acción proactiva, que todo ser humano e institución que pertenece a una comunidad debe asumir frente a las situaciones de riesgo o amenaza. Al respecto la II Conferencia Regional de la Educación Superior en América Latina y el Caribe. CRES. (UNESCO 2008) plantea como una estrategia efectiva en cuanto a la pertinencia la conformación de redes académicas donde los expertos investigadores con formación deontológica trabajen de forma solidaria en la construcción y ejecución de proyectos que solucionen problemas que afectan de forma similar y simultanea territorios nacionales e internacionales.

Además, debe tenerse en cuenta que la calidad y pertinencia, mantienen estrecha relación con la cobertura, por lo tanto se necesita ampliar el espectro educativo para que sea mayor el porcentaje de accesibilidad a la formación académica, enriquecida con nuevas tecnologías, el desarrollo de procesos investigativos y empresariales, todo esto aunado a la concepción de educación y formación a lo largo de toda la vida, como se plantea en la Conferencia Mundial de Paris (UNESCO, 2009).

En Colombia el interés por el acceso, calidad y pertinencia se vio reflejado en las políticas educativas tendientes a crear un sistema de información sólido sobre educación, llamado Sistema Nacional de Información de la Educación Superior (SNIES) desde el año 1992 con la Ley General de Educación, puesto en marcha de manera definitiva y obligatoria únicamente hasta el año 2010 con los correspondientes procesos de mejoramiento y ajustes posteriores. El SNIES es el encargado de recopilar y consolidar datos e información relevante de las instituciones de educación superior, siendo a la vez fuente de consulta obligada para atender procesos de planeación, monitoreo, vigilancia; además divulga información confiable y oficial como indicadores y estadísticas necesarias para el sector educativo.

Las Instituciones de Educación Superior (IES) están obligadas a alimentar el sistema para garantizar la solides, validez y oportunidad de la información que suministra. Sin embargo, al consultar la plataforma del Ministerio de Educación Nacional (MEN), en el 2018, los datos que presentan están consolidados a 2015, los de 2016 están publicados por institución y no de manera general; los de 2017 aún no están disponibles. El informe sobre cobertura se observa en la figura 1. 
Figura 1: Tasa de cobertura en Educación Superior de Colombia (ESC).

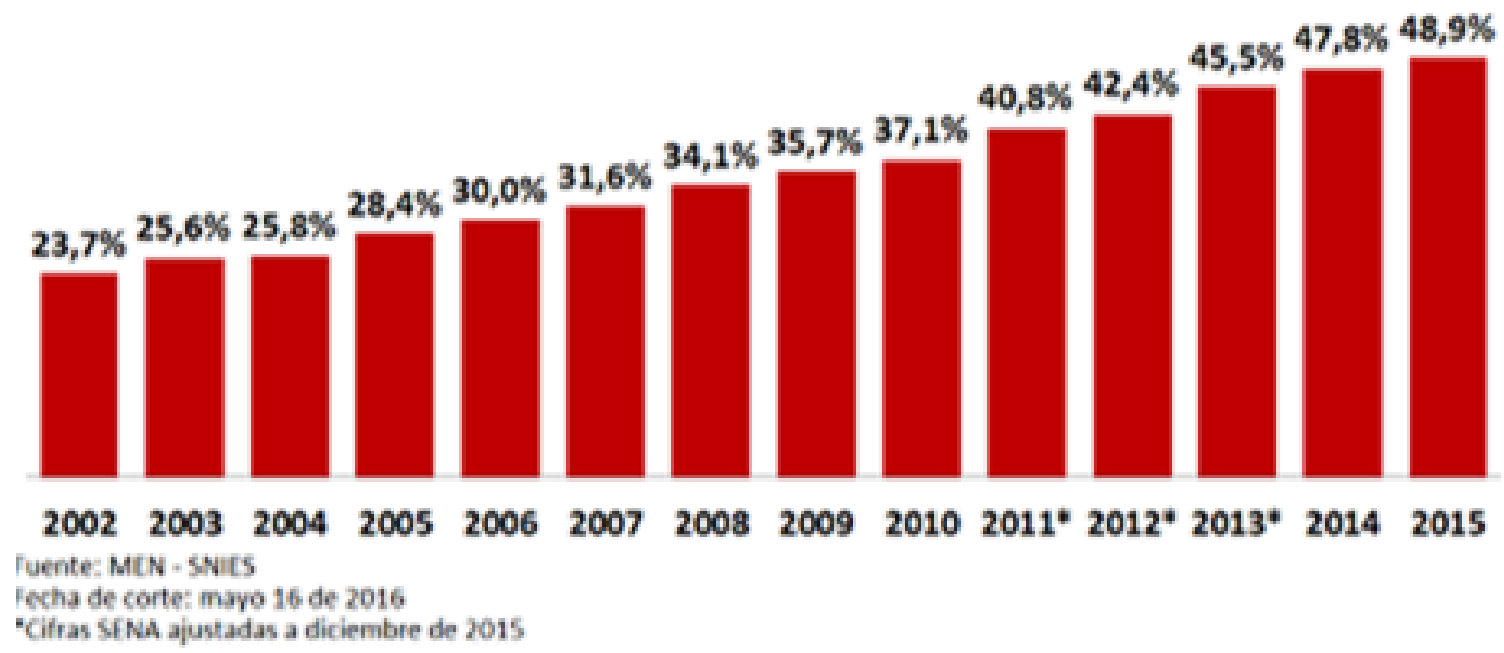

Fuente: Ministerio de Educación Nacional- SNIES. 2018

Se observa que, aunque la cobertura de ESC ha aumentado considerablemente desde el año 2002 hasta el 2015 en un $25.2 \%$, situación que, aunque a simple vista es alentadora no corresponde al cumplimiento del compromiso adquirido por el Estado colombiano con la UNESCO y la comunidad nacional e internacional.

De igual forma, tras acciones del Estado colombiano con el fin de gestionar, promover, mejorar y asegurar la calidad de las IES, de los programas que se ofrecen, así como mediciones sobre el impacto en los estudiantes, actualmente se cuenta con el Sistema de Aseguramiento de la Calidad en Educación Superior (SACES) a través del cual las IES surten los procesos de reconocimiento, aprobación, registro calificado, apertura de seccionales, entre otros. En la última década el Estado ha avanzado en el aseguramiento de la calidad ejerciendo control y vigilancia tanto de las IES como de los programas que se ofrecen, pero no de manera significativa según la proyección de los compromisos adquiridos, como se refleja en el Índice de Progreso de la Educación Superior (IPES) que está compuesto por indicadores de acceso, logro educativo y calidad de la educación. (MEN, SNIES, 2018).

Otra estrategia es la implementación del Sistema para la Prevención de la Deserción en las Instituciones de Educación Superior (SPADIES), que brinda información sobre deserción, graduación y los factores que afectan la permanencia y permite efectuar la trazabilidad de las situaciones académicas y socio económicas de los estudiantes. Este sistema suministra la información requerida para calcular el Índice de Logro (IL), que a su vez es utilizado para calcular el IPES. 
El Observatorio Laboral para la Educación (OLE), es el sistema de información especializado para el análisis de la pertinencia en la educación superior, permite hacer el seguimiento a los graduados del país y su empleabilidad en el mercado laboral colombiano elementos fundamentales en el proceso de mejoramiento de la calidad y la pertinencia. (Observatorio Laboral para la Educación, 2018).

Con estos sistemas de información Colombia ha avanzado en su objetivo de mejorar y garantizar la calidad y la pertinencia de los programas de Educación Superior, sin embargo, aún se está lejos de alcanzar las metas propuestas en la agenda Educación-2030 (UNESCO, 2015).

En Colombia el MEN toma como referente lo realizado por el Instituto de Innovación Educativa del Instituto Tecnológico y de Estudios Superiores de Monterrey, México y calcula anualmente el Índice de Progreso de la Educación Superior (IPES), cifra que se convierte en referente indispensable para dar cuenta de los avances de la ES en el país y sus diferentes regiones. El IPES está compuesto a su vez de tres indicadores: de calidad, que lo constituye el porcentaje de estudiantes con mejores promedios en las pruebas de estado Saber Pro; indicador de acceso, conformado por el número de estudiantes matriculados según lugar de origen respecto a la población entre 17 y 21 años y el indicador de logro, que corresponde al porcentaje de estudiantes graduados hasta 14 semestres después de matriculados. (MEN. SNIES. 2018). En la figura 2 se presenta el IPES y sus componentes calculados hasta el año 2015.

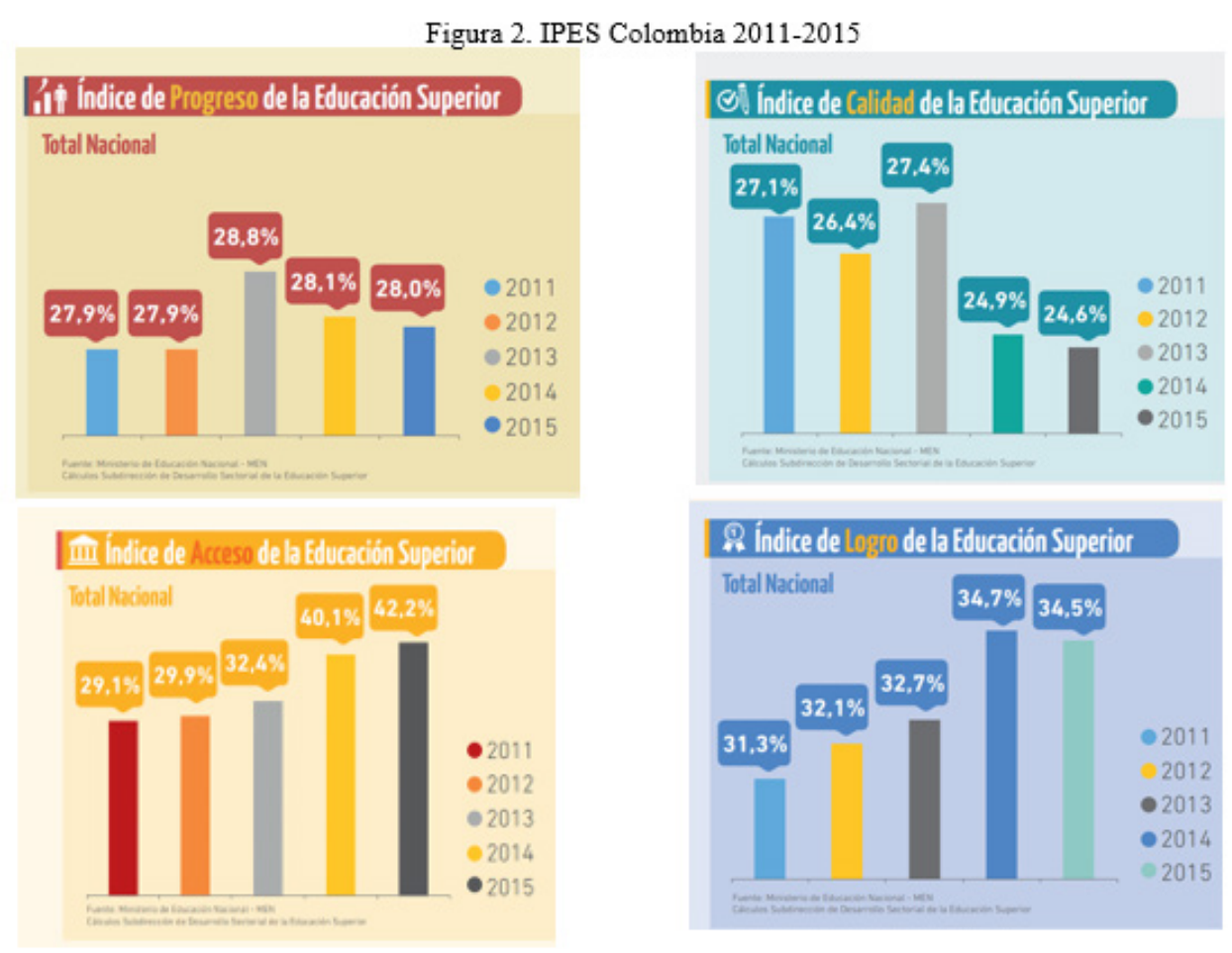

Fuente: Ministerio de Educación Nacional. SNIES- IPES 2018. 
De las gráficas se deduce que Colombia durante los últimos años no ha tenido progreso en la ES y que su indicador muestra una cifra exigua de $28 \%$ en el 2015 ; a su vez la calidad también muestra un descenso preocupante en los últimos años, teniéndose un indicador de calidad para el 2015 de solo el $24.6 \%$. En cuanto al acceso, sí se percibe un aumento creciente a través de los años registrando un $42.2 \%$ en el 2015 , cifra que aún es preocupante porque no llega siquiera al $50 \%$. El indicador de logro presenta un 34,5\% en el año 2015, también menor respecto al año anterior. Ante este panorama el tema de calidad y pertinencia deben acogerse con carácter de urgencia y prioridad en la agenda nacional si se quiere llegar a una aproximación más significativa con los objetivos de la agenda mundial y de desarrollo sostenible.

\section{Educación para todos (EPT) factor humanista en la educación}

El postulado y finalidad de educación para todos (EPT) nace con La Conferencia de Jomtien (UNESCO, 1990), que representó sin duda el impulso a nivel mundial, regional y nacional a la educación, toda vez que generó un compromiso firme con el desarrollo humano, expresado en su objetivo fundamental: "cada persona, niño, joven o adulto deberá estar en condiciones de aprovechar las oportunidades educativas ofrecidas para satisfacer sus necesidades básicas de aprendizaje". (p. 8). A partir de ese año los estados se comprometieron a extender los programas educativos de tal forma que la accesibilidad fuese general, porque la educación como bien público pertenece al colectivo y debe ofrecerse por igual a cualquier ciudadano en cualquier lugar del planeta.

La visión humanista de la educación se enfoca hacia la prestación de un servicio eficaz y efectivo, que propicie la facilidad de ingreso, disminución de la discriminación e igualdad de oportunidades para todos y el fortalecer la permanencia dentro del sistema educativo. Al respecto la CMSE (UNESCO, 1998), plantea: la necesidad de facilitar el ingreso a toda persona que se interesa por el aprendizaje sin distingo de razas, sexo, idioma, religión, condición física, cultural o económica. Lo importante de este planteamiento es establecer políticas claras para no sólo facilitar el ingreso sino asegurar la permanencia tranquila y feliz que conlleve a la culminación de ciclos académicos de seres humanos formados holísticamente, sin menoscabo de su integridad y personalidad. A partir de esta conferencia, la inclusión ha sido tema de obligatoria discusión en todo encuentro de educación pero es en el año 2015, con la Declaración de Incheon, (UNESCO 2015) donde toma un lugar de privilegio en cuanto a que se le asigna como eje central dentro del Objetivo de Desarrollo Sostenible (ODS) N.4 "Garantizar una educación inclusiva y equitativa de calidad y promover oportunidades de aprendizaje permanente para todos". 
La Constitución Política de Colombia de 1886 estableció la educación como un derecho civil y garantía social, posteriormente en la Constitución Nacional (CN) de 1991 vigente, en su artículo 44 elevó la educación a un derecho fundamental y establece la educación como un derecho y un servicio público que tiene función social; formará en el respeto a los derechos humanos, la paz y la democracia; el Estado, la sociedad y la familia son responsables de la educación; establece la obligatoriedad y gratuidad para un año de preescolar y nueve de educación básica (art. 67), permite la educación privada (art. 68), garantiza la autonomía universitaria y el fortalecimiento de la investigación científica (art 69).

Como resultado de los movimientos sociales reflexivos en torno a la educación que tuvieron lugar en América Latina y del Caribe años 70 y 80, el gobierno colombiano se vio en la necesidad de promulgar la Ley 30 de 1992 o Ley de Educación Superior, la cual reitera los principios constitucionales sobre educación: es un derecho fundamental, un servicio público, orientada hacia la reflexión, autonomía, libertad y pluralismo ideológico, para la enseñanza, el aprendizaje, investigación, desarrollo científico y el avance tecnológico. Se crea el Consejo Nacional de Educación Superior (CESU), que cumple funciones de inspección y vigilancia principalmente. Mediante esta ley nace El Sistema Nacional de Acreditación para las instituciones de Educación Superior que actualmente es el Sistema de Aseguramiento de la Calidad en Educación Superior (SACES). (Ministerio de Educación Nacional, 1992).

Es importante anotar que en el 2011 se presentó una reforma a la ley 30 por parte del gobierno colombiano, pero por falta de acuerdos, resistencia del sector estudiantil y las instituciones se tomó la decisión de retirarla del congreso de la república y archivarla. El gobierno nacional consiente de la necesidad de construir la política pública de ES que incluya las estrategias planteadas por la UNESCO organiza un debate público nacional de donde surge el Acuerdo por lo superior 2034 (MEN, 2014), que se centra en diez temas fundamentales siendo el primero de ellos, educación inclusiva, acceso, permanencia y graduación.

De igual manera el Ministerio de Educación Nacional, presenta dentro de los lineamientos de la política de educación superior inclusiva, las seis características: participación, diversidad, interculturalidad, equidad, calidad y pertinencia, ilustrados en la figura 3. (Ministerio de Educación Nacional, 2013). 
Figura 3. Características de la educación inclusiva en Colombia.

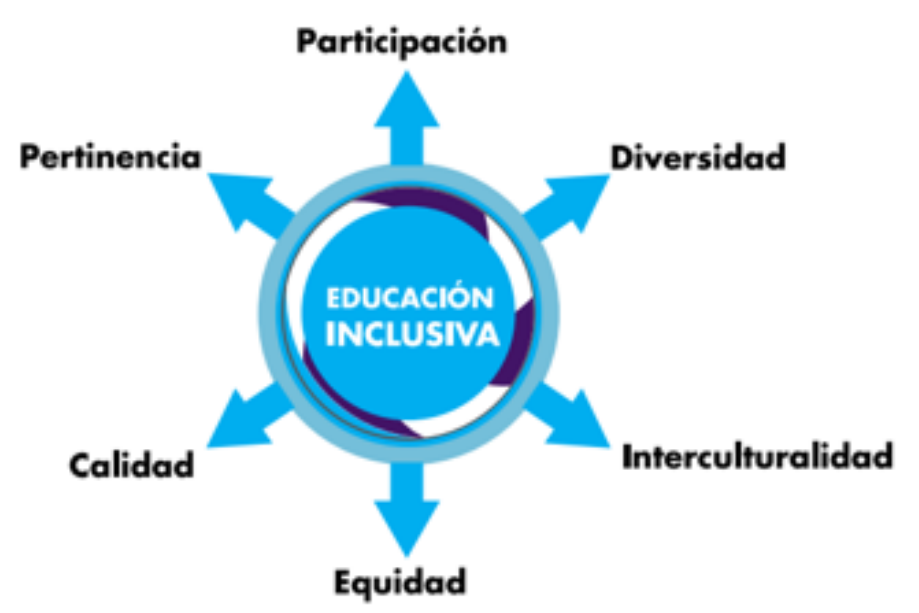

Fuente: MEN, Lineamientos de la política de educación superior inclusiva (2013).

Colombia, en su interés por brindar una ES inclusiva y EPT, ha pasado por un proceso de diversas etapas donde se han presentado variaciones conceptuales y enfoques más pertinentes proyectado a cumplir las metas globales de la Declaración de Incheon, Educación 2030 (UNESCO, 2015) y compromisos nacionales plasmados en el Acuerdo por lo Superior 2034.

Colombia como país participante de los principales encuentros mundiales sobre educación y de desarrollo sostenible, ha vinculado en sus políticas de estado sobre educación las estrategias recomendadas en los diferentes acuerdos y declaraciones; sin embargo en la realidad se aprecia que se han hecho esfuerzos, pero estos no han tenido la trascendencia que se necesita para lograr una EPT de calidad, pertinente e inclusiva. Lo anterior obedece a la falta de continuidad en los planes y programas gubernamentales, porque durante un gobierno no se concluyen y el nuevo gobierno los delega e inicia unos nuevos por el interés de generar impacto en su mandato; la falta de recursos financieros suficientes que cubran más allá de la infraestructura y se direccionen al fortalecimiento de la inclusión, acceso y permanencia, en todas las regiones del país; no existe una coherencia entre las políticas trazadas por el del Estado con las implementadas en las IES.

Otra barrera que dificulta la EPT y la inclusión, se debe a la falta presencia física de IES y de conectividad en algunas regiones apartadas del país que impide el acceso de la ES o a la educación virtual superior, de tal forma que el estudiante interesado en continuar sus estudios superiores debe migrar con las consecuentes dificultades económicas, familiares y sociales que le generan. 
La proliferación de universidades informales e instituciones de formación técnica e intermedia a bajos costos disminuyen el ingreso de estudiantes a programas certificados y acreditados en detrimento de un ES de calidad. Ante esta situación le corresponde al Estado fortalecer el Sistema de Aseguramiento de la Calidad en Educación Superior (SACES) para ejercer función de inspección y vigilancia verbigracia del aseguramiento de la calidad, acceso y pertinencia y así contrarrestar el mercantilismo y la formación superficial.

La educación para todos (EPT) como factor humanista en la educación, presenta hoy una mirada holística, más humanista y pertinente, dirigida hacia el desarrollo humano, social, ambiental, económico y sostenible, capaz de lograr la integración de múltiples dimensiones del ser humano mediante procesos dialógicos interculturales de respeto por el otro, de inclusión, de justicia, de equidad, de paz, democracia, derechos humanos y tolerancia, generadores de una mayor cohesión y desarrollo social construyendo, además, el concepto de ciudadanía mundial y formación holologica comprendida como el ejercicio profesional y educativo como un continuum (Barrera, 2013), es decir a lo largo de toda la vida de tal forma que el proceso educativo no es limitado a la edad del individuo, muy por el contrario se surte permanentemente; el ser aprende y enseña en cada instante de su existencia, recibe y procesa información, se inquieta por los fenómenos que observa, produce y comparte ideas, conocimiento. Por tanto, es nuestra responsabilidad como agentes educativos promover no solo una educación para todos, sino proyectarla a que el estudiante logre una concepción de formación holologica, es decir durante toda su vida.

\section{Educación y sostenibilidad: una fusión necesaria}

La educación tiene la RS de generar cambios, progresos y beneficios para todos los habitantes en los diferentes contextos, lograrlo requiere desarrollar proyectos integradores entre gobiernos e instituciones que apoyen los procesos investigativos, tecnológicos y comunicativos, en pro del buen vivir y la sostenibilidad. "La sostenibilidad ha surgido como preocupación esencial del desarrollo para hacer frente al cambio climático, el deterioro de recursos naturales vitales, como el agua, y la pérdida de la biodiversidad". (UNESCO, 2014, p.22).

De manera semejante la UNESCO (2015), establece como meta al 2030, educar a los estudiantes hacía la conciencia ecológica que promueva el desarrollo sostenible. Se aprecia entonces la importancia otorgada a la relación en doble vía entre educación y sostenibilidad, para que desde las aulas se interiorice el compromiso por el cuidado y conservación de la biodiversidad, donde 
el estudiante de ES, apropie competencias ciudadanas que lo lleven a aportar desde la academia y los procesos investigativos, soluciones a problemas como la destrucción de la capa de ozono, el agotamiento de recursos naturales, el cambio climático, las pandemias, entre otros, para combatir la actitud pasiva y pensamientos reduccionistas frente a la realidad latente de problemas sociales, culturales y ambientales, a nivel local, regional y global. Las IES deben incluir en sus planes de estudio, como lo propone UNESCO (2014), “...los principios de justicia social y económica, igualdad y responsabilidad medioambiental, que constituyen los pilares del desarrollo sostenible". (p. 42).

En Colombia la Constitución Nacional dentro del capítulo tres de los derechos colectivos y del ambiente, establece la responsabilidad del Estado en la conservación del medio ambiente y los recursos naturales, para garantizar el desarrollo sostenible. El direccionamiento de estas políticas está bajo la responsabilidad del Ministerio de Ambiente y Desarrollo Sostenible, que a su vez dirige el Sistema Nacional Ambiental SINA, cuya función principal es asegurar la adopción y ejecución de las políticas, planes y programas y proyectos ambientales y sostenibles. De la misma manera la empresa privada cuenta con el acompañamiento del Consejo Empresarial Colombiano para el Desarrollo Sostenible, (CECODES), para lograr el equilibrio entre los objetivos empresariales, sociales y ambientales, acordes con el desarrollo sostenible del país; esta organización considera que los actores responsables del desarrollo sostenible son: la empresa sostenible, el gobierno, la sociedad, la academia y las Organizaciones no gubernamentales (ONG). El CECODES es:

El capítulo colombiano del World Business Council for Sustainable Development(WBCSD), el cual reúne a 200 compañías líderes en el mundo, unidas por el compromiso con el desarrollo sostenible a través de sus tres pilares: crecimiento económico, balance ecológico y progreso social. (CECODES, 2015).

De manera simultánea en el sector educativo se han adoptado acciones para formar en el desarrollo sostenible, es el caso de los Propuestas Ambientales Educativas (PRAE, a nivel nacional) organismos dirigido a la educación medio ambiental que se implementa en las Instituciones Educativas como Proyecto Ambiental Escolar. A nivel universitario las IES, se han vinculado con el desarrollo sostenible, ejecutando programas de responsabilidad social y sostenibilidad en línea con los ODS.

A partir de lo consignado anteriormente se evidencia que el tema de sostenibilidad es de interés y preocupación general desde el gobierno nacional, las empresas del sector público y privado, la academia y medios de comunicación y organizaciones sociales, por ello han emprendido diferentes 
acciones en un trabajo mancomunado tendiente a promover, prevenir y proteger entornos saludables en pro de la población actual y asegurar un futuro sostenible hacía las generaciones venideras, en cumplimiento de los ODS; los anteriores actores responsables del desarrollo sostenible coinciden en considerar la educación, en sus diferentes niveles, como el medio más eficaz para lograr la conciencia ecológica y formación deontológica, elementos indispensables en la construcción de un mundo mejor.

No obstante, las buenas acciones ya mencionadas en el contexto nacional, existe una dicotomía entre lo que se espera en beneficio del planeta y lo que se observa en la realidad, debido a que aún prevalecen los intereses particulares sobre los comunitarios o generales, donde el día a día nos muestra el uso inadecuado de los recursos naturales, la falta de conciencia ecológica y la insuficiente orientación deontológica de los profesionales que asumen macro proyectos industriales en los lugares más recónditos, para beneficiarse económicamente sin importar los daños ambientales que ocasionan, como es el caso particular de Colombia, que en los últimos años se han presentado catástrofes ambientales que dejan entrever el manejo oportunista de la minería ilegal, construcción de hidroeléctricas sin las medidas de bioseguridad, vías de comunicación inconclusas, entre otras; surge la inquietud : ¿La ES está formando profesionales con RS?, la respuesta parece ser evidente: no, entonces las IES deben replantear no solo la formación académica de sus profesionales sino su formación ética y compromiso social para que los egresados cumplan a satisfacción con su desempeño profesional, humanista y deontológico; de igual forma el seguimiento y control que deben ejercer las entidades del estado esta permeada por la deshonestidad y otros vicios de la sociedad colombiana que impiden cumplir con sus funciones de una manera responsable, para evitar el panorama ya descrito.

\section{Investigación y educación, factores prosociales}

Los procesos investigativos deben estar presentes en elámbito educativo, en razón a que laindagación y estudio de fenómenos culturales y sociales conllevan a la producción de conocimiento, misión fundamental de la educación. Son las instituciones educativas las responsables de transversalizar: los modelos, los proyectos educativos y el currículo en todas sus dimensiones, a través de la investigación, en aras de cumplir con la responsabilidad social, de mejorar las condiciones de vida y aprovechamiento de los recursos, en los diferentes sectores de la economía local, nacional e internacional. En la revisión de la normativa internacional se encuentra el énfasis constante en la investigación, se le reconoce su importancia y necesidad; en razón a esto se presenta a continuación en la tabla 1 la relevancia otorgada a esta temática, en cada documento seleccionado. 
Tabla 1. La investigación, una temática ineludible.

\begin{tabular}{|c|c|c|c|c|c|}
\hline $\begin{array}{c}1998 \\
\text { Conferencia } \\
\text { Mundial sobre la } \\
\text { Educación Superior } \\
\text { para el siglo XXI. } \\
\text { CMSE. (Paris, 1998) }\end{array}$ & $\begin{array}{c}2000 \\
\text { (UNESCO, } \\
\text { Dakar, 2000) }\end{array}$ & $\begin{array}{l}2008 \\
\text { II Conferencia } \\
\text { Regional de la } \\
\text { Educación Superior } \\
\text { en América Latina y } \\
\text { el Caribe. CRES. }\end{array}$ & $\begin{array}{c}2009 \\
\text { Conferencia } \\
\text { Mundial (Paris, } \\
\text { 2009). La nueva } \\
\text { dinámica de la } \\
\text { educación superior } \\
\text { y la investigación } \\
\text { para el cambio } \\
\text { social y el } \\
\text { desarrollo }\end{array}$ & $\begin{array}{c}2014 \\
\text { Replantear la } \\
\text { Educación. UNESCO }\end{array}$ & $\begin{array}{l}2015 \\
\text { Declaración de } \\
\text { Incheon }\end{array}$ \\
\hline $\begin{array}{l}\text { La misión de educar, } \\
\text { formar y realizar } \\
\text { investigaciones. } \\
\text { Utilización del } \\
\text { conocimiento en } \\
\text { servicio de la } \\
\text { comunidad. }\end{array}$ & $\begin{array}{l}\text { Plantea: "...ofrecer } \\
\text { a los docentes una } \\
\text { formación de alto } \\
\text { nivel académico, } \\
\text { vinculada con la } \\
\text { investigación y la } \\
\text { capacidad para } \\
\text { producir } \\
\text { Innovaciones". } \\
\text { (UNESCO, } \\
2000,0.40 \text { ) }\end{array}$ & \begin{tabular}{lr}
\multicolumn{2}{l}{ Políticas nacionales, } \\
regionales \\
institucionales que \\
transformen la \\
relación entre los \\
grupos & de \\
investigación & \\
académica y los \\
usuarios & del \\
conocimiento &
\end{tabular} & $\begin{array}{l}\text { Considera } \\
\text { fundamental el } \\
\text { apoyo a la } \\
\text { innovación, la } \\
\text { investigación y la } \\
\text { interdisciplinarieda } \\
\text { d. }\end{array}$ & $\begin{array}{l}\text {...responder a la } \\
\text { demanda mundial } \\
\text { masiva de títulos } \\
\text { profesionales, } \\
\text { manteniendo al } \\
\text { mismo tiempo su } \\
\text { función primordial } \\
\text { de formar para la } \\
\text { investigación } \\
\text { (UNESCO, 2014, } \\
\text { p.55) }\end{array}$ & $\begin{array}{l}\text { crear capacidades } \\
\text { sostenibles locales } \\
\text { y nacionales para la } \\
\text { investigación } \\
\text { cualitativa } \\
\text { cuantitativa. } \\
\text { (UNESCO, } \\
2015, p .57 \text { ) }\end{array}$ \\
\hline
\end{tabular}

Fuente: propia a partir de la lectura de documentos seleccionados.

Indiscutiblemente la investigación debe estar presente en todo proceso educativo, incluirse en la academia, esto implica que todos los agentes educativos reciban la capacitación necesaria para orientar procesos investigativos que redunden en el beneficio de la comunidad local y global, toda vez que la finalidad de ésta es: prever a la sociedad de elementos, métodos y conceptos que aporten de manera directa en el mejoramiento de la calidad de vida de la humanidad, construir comunidades científicas interdisciplinarias y tras disciplinares que permitan avanzar de manera colectiva hacía una sociedad más desarrollada y preparada científicamente.

La dificultad radica en que su desarrollo necesita además de voluntad política, de recursos humanos altamente capacitados y recursos financieros para realizar inversiones a largo plazo. También se presenta la llamada fuga de cerebros, que afecta el desarrollo de la región de origen de los profesionales, porque los avances y beneficios no se reflejan directamente en el contexto particular, afectando el principio pro social de la investigación.

La investigación en Colombia esta direccionada por el Departamento Administrativo de Ciencia, Tecnología e Innovación, COLCIENCIAS, (CTeI), que depende de la presidencia de la república y lidera el sistema nacional de ciencia, tecnología e innovación.

La entidad enfoca sus esfuerzos en 4 grandes áreas de trabajo: educación para la investigación, Investigación, Innovación, mentalidad y cultura científica con el objetivo de construir política pública, científica, tecnológica y de innovación que aporte al desarrollo sostenible y construcción 
de conocimiento científico, elementos fundamentales para propiciar una vida digna a los habitantes del territorio colombiano.

No hay duda que la Ciencia, la Tecnología y la Innovación (CTI) es generadora de nuevos conocimientos, que se constituye a la vez en el motor para el desarrollo económico del país, su crecimiento sustentable y en una mayor equidad social, a la vez que afianza la paz, la democracia y la solidaridad, como una forma para hacer visible la presencia real del estado en la vida de la nación, por tanto es prioritario y urgente establecer políticas gubernamentales donde se involucren la CTI de manera transversal en todos los planes, con la correspondiente asignación de recursos lo suficientemente fuertes para que cada uno de sus actores, como las comunidades científicas, las empresas, los gobiernos locales, las IES, las IE, hasta los pequeños grupos de investigación locales puedan llevar a cabo sus objetivos. Se requiere fortalecer el Sistema Nacional de Ciencia y Tecnología e Innovación con la intencionalidad de crear riqueza, desarrollo y bienestar social, priorizando en el recurso humano y direccionando la CTI al cumplimiento de los objetivos del desarrollo sostenible, mediante la transferencia de conocimiento generado en investigaciones científicas en áreas como cambio climático, energías limpias, seguridad energética, biodiversidad, infraestructura vial, seguridad alimentaria y de salud y se lleven a la praxis.

Es urgente entonces que el gobierno nacional sea verdaderamente consiente que se deben asignar recursos suficientes, significativos y a largo plazo para la CTI, tal como lo recomiendan los organismos internacionales y lo solicitan permanentemente los organismos nacionales; solo así se podrá salir adelante social y sustentablemente disminuyendo la brecha existente en materia de investigación. En la figura 4 se muestran los recursos asignados a Colciencias desde 2010 a 2018.

Figura 4: Presupuesto COLCIENCIAS (2010-2018)

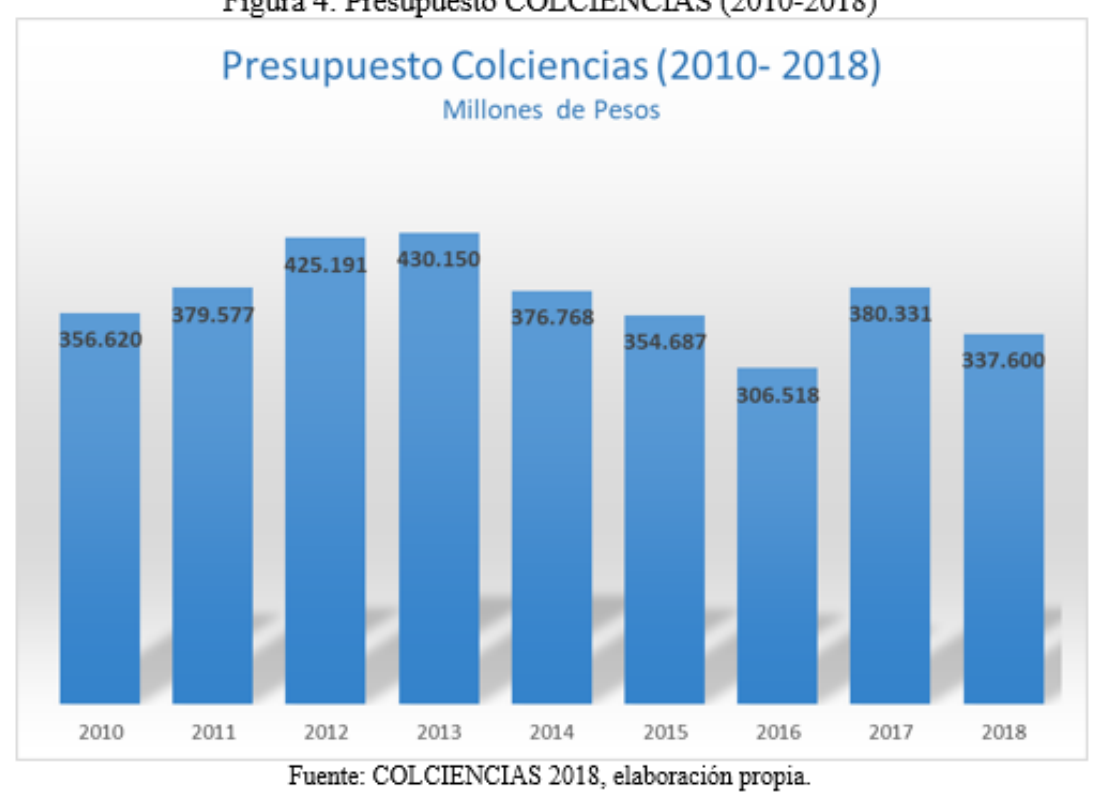


Como se puede observar el presupuesto para la ICT sufrió una fuerte disminución durante los años 2015, 2016, con un ligero incremento en el 2017, para de nuevo decaer en el 2018 a 337.600 millones de pesos, cifra que representa una diferencia de 92.550 millones de pesos menos respecto al año 2013 en el que se dio una transferencia de recursos de 430.150 millones de pesos. Estas políticas desestabilizan cualquier sistema y frena los esfuerzos que se pretenden hacer en materia de ICT. Se reitera entonces la importancia de contar con recursos suficientes, pero principalmente estables para que se puedan incentivar verdaderamente la ICTeI.

El Sistema Nacional de Ciencia, Tecnología e Innovación también da cuenta sobre existencia de 5.207 grupos de investigación en ciencia tecnología e innovación, distribuidos con los siguientes porcentajes según el área de investigación: 37\% en ciencias humanas, sociales y educación, 17\% en salud, $12 \%$ en ciencias básicas, $8 \%$ en ingeniería, $6 \%$ en ambiente, biodiversidad y habitad, $6 \%$ en $\mathrm{TIC}^{\prime} \mathrm{s}, 6 \%$ en ciencias agropecuarias, $2 \%$ en energía y minería, $2 \%$ en biotecnología, $1 \%$ en seguridad y defensa, 1\% en recursos hidrobiológicos y 3\% que no aplica. Además, registra 13001 investigadores registrados y reconocidos en todo el país. (COLCIENCIAS 2018).

Esta realidad visibiliza el bajo porcentaje de presencia de la academia colombiana en el área investigativa, por lo tanto les compete a los agentes educativos y principalmente a los profesionales en educación, vincularse a grupos de investigación que fortalezcan los procesos de CTeI, desde los contextos institucionales locales hasta los de mayor escala a nivel nacional e internacional, misión que deben asumir las IES para que los estudiantes activos y los egresados se mantengan activos en la producción del conocimiento científico como fundamento pro social en la humanidad.

\section{Interculturalismo e Internacionalización, nueva dialógica en la escuela}

A partir de la globalización se genera un intercambio cultural a nivel del planeta, porque gracias a los avances tecnológicos y convenios internacionales, los pueblos han iniciado un contacto más continuo y cercano, facilitando así la adaptabilidad y diálogo de culturas, pasando del multiculturalismo al interculturalismo. "La educación facilita el diálogo intercultural y promueve el respeto de la diversidad cultural, religiosa y lingüística, que son vitales para la cohesión social y la justicia” (UNESCO, 2015, p.24), razón por la cual al interior de las IES se debe generar un ambiente de cordialidad, respeto, equidad y aceptación a la diferencia. 
La nueva mirada holística de la educación es más humanista y pertinente, dirigida hacia el desarrollo humano, social, ambiental, económico y sostenible, capaz de lograr la integración de múltiples dimensiones del ser humano mediante procesos dialógicos interculturales de respeto por el otro, de inclusión, de justicia, de equidad, de paz, democracia, derechos humanos y tolerancia, generadores de una mayor cohesión y desarrollo social construyendo, además, el concepto de ciudadanía mundial.

De igual manera la ES debe asegurar el intercambio universal de conocimientos avanzados basados en el respeto a la diversidad, la transculturalidad e internacionalización sin despegar la mirada del contexto local y sin menoscabo de la soberanía nacional, como lo deja claro la CMSE (1998):

La calidad requiere también que la enseñanza superior esté caracterizada por su dimensión internacional: el intercambio de conocimientos, la creación de sistemas interactivos, la movilidad de profesores y estudiantes y los proyectos de investigación internacionales, aun cuando se tengan debidamente en cuenta los valores culturales y las situaciones nacionales. (p.33).

La internacionalización de la ES requiere dejar claro los criterios para procesos de movilidad, homologación, acreditación, convalidación, financiamiento y los incentivos para el retorno del personal capacitado a su lugar de origen; la educabilidad o el conjunto de elementos imprescindibles para que se realice todo acto educativo, implica que los países que establecen convenios internacionales promuevan la adaptabilidad de los planes y programas de estudio, capaciten a los profesores en metodologías flexibles, mejoren las condiciones de conectividad, amplíen el espectro del uso de las TIC y organicen redes académicas internacionales en pro del mejoramiento de la educación.

En Colombia el MEN para facilitar la internacionalización de la educación mantiene convenios con los siguientes países: Argentina, Chile, España, Bulgaria, Uruguay, Perú, Costa Rica, México, Alemania, Brasil, Egipto, Corea, Cuba, Checoslovaquia, Ecuador, Francia, Guatemala, Honduras, Hungría, India, Italia, Nicaragua, Panamá, Polonia, República Dominicana, Irlanda y Rumanía (MEN, 2018). Se cuenta entonces con una gran variedad de opciones que facilitan la capacitación y orientación profesional para que los estudiantes interesados apliquen según sus necesidades y competencias, la dificultad está en que no se hace la suficiente divulgación y motivación para que los jóvenes accedan a estas facilidades y tengan una oportunidad de internacionalizarse, ser exitosos profesionalmente. 
Para efectos de convalidación de títulos otorgados por IES extranjeras o legalmente reconocidas a nivel internacional, el MEN en cumplimiento a lo expresado por la ley 30 de 1992, se orienta por la Resolución 20797 del 09 de octubre de 2017, donde se expresa claramente que "la globalización y la internacionalización de la educación son determinantes en los procesos de aseguramiento de la calidad de los sistemas educativos de un país...” (Ministerio de Educación Nacional, 2017, p.2). La resolución en mención establece el proceso de convalidación, que inicia con la radicación de documentos hasta la evaluación académica y decisión final .Si el proceso de convalidación está estructurado legalmente con una entidad y personal responsable, además de requisitos definidos, ¿Por qué se presentan anomalías en la convalidación de títulos? ¿Se aplican los protocolos establecidos de manera rigurosa y disciplinada?, se mantiene la misma falencia a lo largo de la lectura de la realidad nacional, se requieren realizar procesos de seguimiento y control a todo nivel de las instituciones para que los valores éticos de responsabilidad y honestidad estén presentes durante toda diligencia o tramite a pequeña o gran escala.

Para facilitar la accesibilidad e internacionalización de la ES se cuenta en Colombia con El Instituto Colombiano de Crédito Educativo y Estudios Técnicos en el Exterior - ICETEX, entidad del Estado que promueve la financiación a través de créditos educativos y otorgamiento de becas en el extranjero, a estudiantes de escasos recursos con el interés de aumentar el ingreso, permanencia y titulación en ES a nivel nacional e internacional. En la figura 5 se aprecia el número de becas utilizadas y no utilizadas, a nivel de doctorado, en el exterior entre los años 2012 y 2016 en Colombia.

Figura 5. Becas asignadas a nivel de doctorado años 2012-2016.

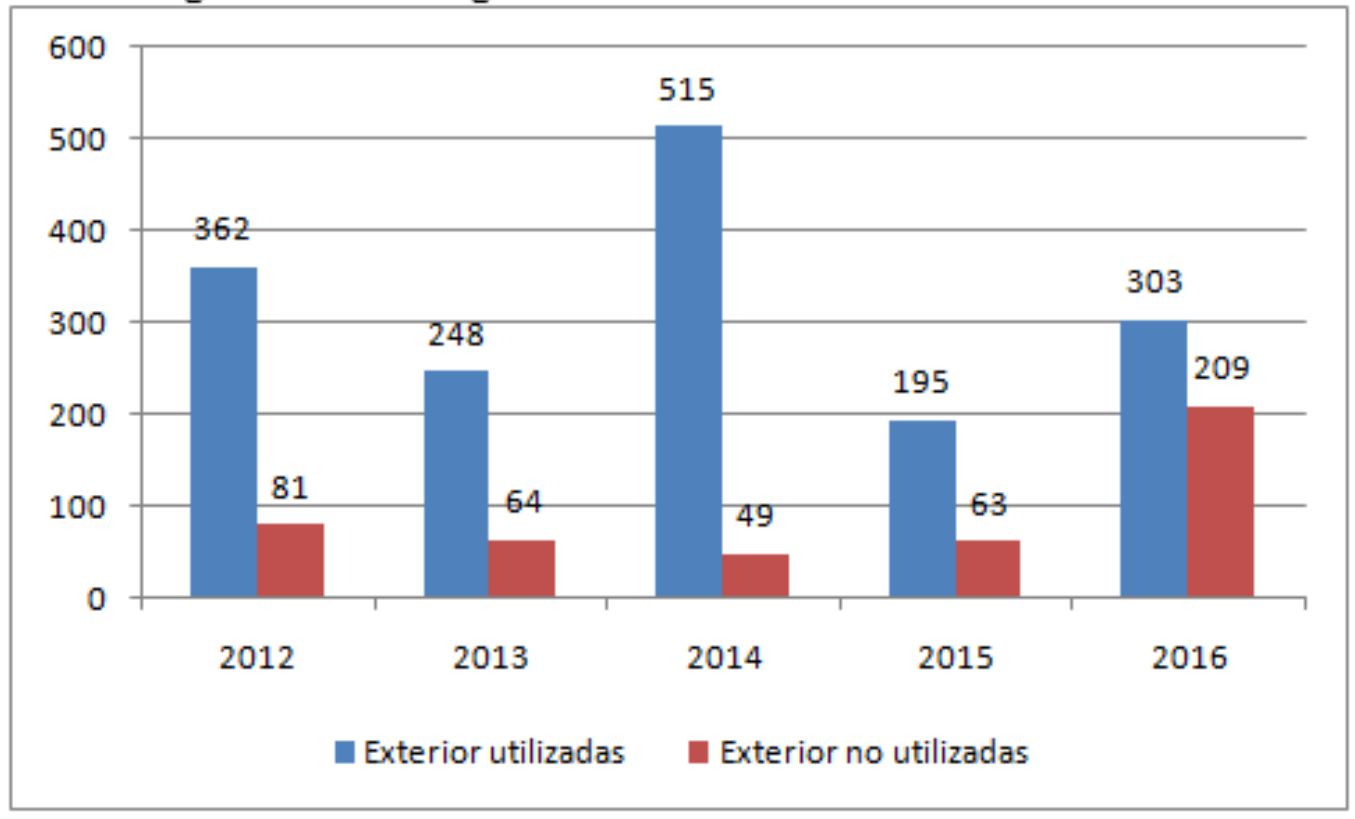

Fuente: elaboración propia a partir de informe COLCIENCIAS (2018). 
Se aprecia en la gráfica una fluctuación año a año en el número de becas asignadas, pero lo más significativo es el aumento de número de becas asignadas pero no utilizadas para el año 2016, porque a pesar de haberse asignado 512 becas para estudio de doctorado en el exterior únicamente se utilizaron 209 becas correspondiente al $41 \%$, lo que ocasiona un rezago en la producción de conocimiento científico, la innovación y formación a lo largo de la vida para todos, en detrimento del desarrollo sostenible (COLCIENCIAS, 2018).

Otro elemento fundamental es la conectividad a nivel nacional, puesto que muchos estudiantes de ES se han vinculado a la modalidad virtual y requieren contar con la facilidad de mantener contacto directo con las IES a través de las plataformas institucionales y para ello necesariamente se requiere contar con el acceso a internet, al respecto en Colombia el Ministerio de las TIC, tiene como objetivo principal en educación, "contribuir con las TIC a la transformación de la educación" (MINTIC, 2018), para lograrlo ha implementado dos retos que son: computadores para educar, con la cual busca propiciar el acceso y apropiación de las TIC y la llamada, inclusión social y digital. Se ha avanzado con la herramienta de los Kioscos vive digital, que consiste en llevar internet a las zonas más apartadas. Es de valorar las estrategias implementadas por el estado para favorecer la educabilidad a nivel de recursos logísticos para promover una formación de calidad.

En el reconocer el interculturalismo e internacionalización como la nueva dialógica en la ES, es evidente que estos dos elementos enriquecen la dinámica social presente en los diferentes niveles educativos, con mayor razón cuando Colombia hoy por hoy, cuenta con representatividad de personal idóneo y brillante en diferentes lugares del planeta y a su vez al territorio colombiano llegan personas de diferentes nacionalidades por intereses económicos, sociales, culturales y académicos, se hace necesario involucrar en el contexto pedagógico didácticas flexibles, pertinentes y diversas, que conlleven a la formación de redes de profesionales interesados en realizar movilizaciones educativas en torno al avance y progreso de la sociedad mundial.

\section{Empleabilidad y Emprendimiento, elementos visionarios de la ES}

El mercado laboral y profesional ha evolucionado de la mano con la globalización por lo tanto las instituciones de educación superior, para continuar vigentes en el mercado competitivo educacional deben actualizar su currículo de tal forma que su oferta sea efectiva para la demanda del sector económico y productivo. 
Así mismo en la actualidad las expectativas sobre la academia son cada vez más amplias, un estudiante en la actualidad siente la necesidad y presión laboral que una vez termina su pregrado, debe iniciar sus estudios de posgrado porque requiere tener una hoja de vida competente para el mundo del trabajo, aspecto positivo porque lo mantiene vinculado dentro de la academia pero en ocasiones es negativo cuando económicamente no tiene los recursos para financiar su especialización y no encuentra opción de un trabajo digno que le ayude a cubrir sus necesidades. Por todo lo anterior es responsabilidad de las IES ofrecer una educación de calidad que se refleje en el perfil de sus egresados, toda vez que sean competentes y emprendedores, para que una vez obtengan su título universitario se sientan empoderados y capaces de enfrentarse al mundo laboral o empresarial. Si y solo si se cumplirá con la meta expuesta en UNESCO, (2015):"aumentar considerablemente el número de jóvenes y adultos que tienen las competencias necesarias, en particular técnicas y profesionales, para acceder al empleo, el trabajo decente y el emprendimiento". (p. 76).

En cuanto a empleabilidad en Colombia el Observatorio Laboral para la Educación (OLE), ha realizado seguimiento a los egresados de la ES, con el fin de interpretar y analizar la correspondencia entre el sector educativo y mercado laboral para mantener informados tanto a los empresarios o empleadores sobre el perfil de los egresados y de igual forma a los estudiantes interesados en vincularse a la ES, sobre la oferta y la demanda de profesionales en el país. El OLE realizó una encuesta de seguimiento a los graduados, puntualizando en tres momentos: momento 1 al año de haberse graduado, momento 3 a los tres años de haberse recibido y momento 5 a los cinco años de contar con su título profesional, sobre la relación entre los conocimientos adquiridos y las actividades laborales que desempeñan que se observan en la figura 6. (OLE. 2018).

Figura 6. Relación entre conocimientos adquiridos y las actividades laborales que desempeñan.

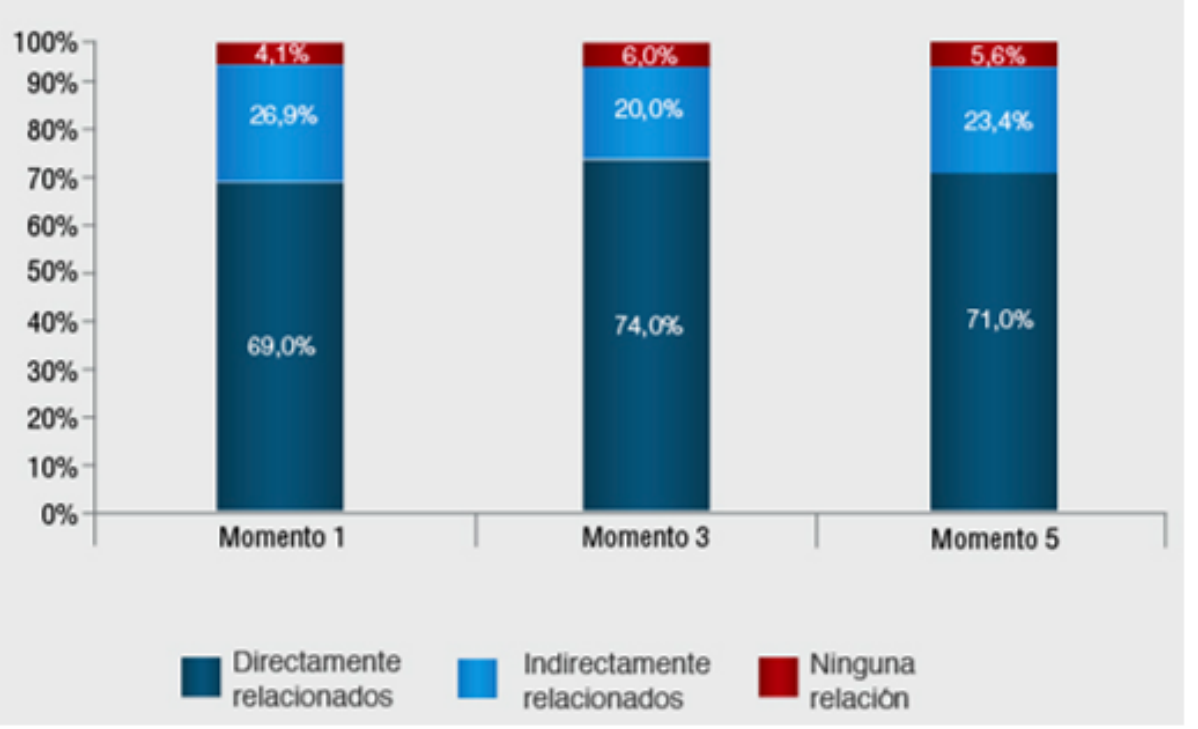

Fuente: Observatorio Laboral para la Educación. 2018 
Al realizar la lectura de los resultados se concluye que el porcentaje mayor corresponde a la coherencia entre la formación académica y la vinculación laboral de los egresados, lo cual deja entrever la pertinencia entre los planes y programas que ofrecen las IES en los contextos del mercado regional y global. También se aprecia que el acceso al empleo acorde con su titulación aumenta después de tres años de culminar su carrera.

Sin embargo, el panorama laboral de Colombia no es alentador, si se tiene en cuenta la tasa de desempleo que suministra el Departamento Administrativo Nacional de Estadística a marzo del presente año es de $9,4 \%$ disminuyendo en un $0.3 \%$, lo que significa que ciento treinta mil personas más están laborando en el presente año. Porque si bien es cierto que las cifras disminuyen, son todavía altas porque están cercanas a los dos dígitos.

(DANE, 2018).

En cuanto a emprendimiento, otro factor preponderante dentro de la visión de una educación pertinente y competente, Colombia se orienta bajo los lineamientos establecidos en la ley 1014 que lo define como:

Una manera de pensar y actuar orientada hacia la creación de riqueza. Es una forma de pensar, razonar y actuar centrada en las oportunidades, planteada con visión global y llevada a cabo mediante un liderazgo equilibrado y la gestión de un riesgo calculado, su resultado es la creación de valor que beneficia a la empresa, la economía y la sociedad. (República de Colombia, 2006, p.1).

La ley de emprendimiento es clara al señalar que: el estado es el responsable de fortalecer el vínculo entre el sistema educativo y el sistema productivo, de tal forma que se incentive la eficiencia y capacitación; toda institución del sector educativo oficial o privado debe brindar formación para el emprendimiento y generación de empresa; las universidades públicas y privadas tendrán la posibilidad de promover planes de negocios en lugar de trabajos de grado.

La realidad colombiana en cuanto a emprendimiento lo presenta el Informe Global Entrepreneurship Monitor (GEM, 2016-2017)), que presenta la información relevante y actualizada y de tendencia sobre el proceso empresarial y sus factores, donde asegura que: Colombia es el quinto país con mayor porcentaje de empresarios Tasa de Actividad Emprendedora (TEA) en el mundo y el tercero en América Latina y el Caribe después de Ecuador y Belice, existe una relación directa entre el nivel educativo y la actividad empresarial. 
En 2016 los colombianos con posgrado crearon un $33.3 \%$ de empresas nacientes y nuevas, en comparación con el 32\% de los colombianos con título universitario y el $30 \%$ de técnicos que evidenciaron emprendimiento. Ver figura 7.

Figura 7. Empresarios nacientes y nuevos TEA, con títulos en ES.

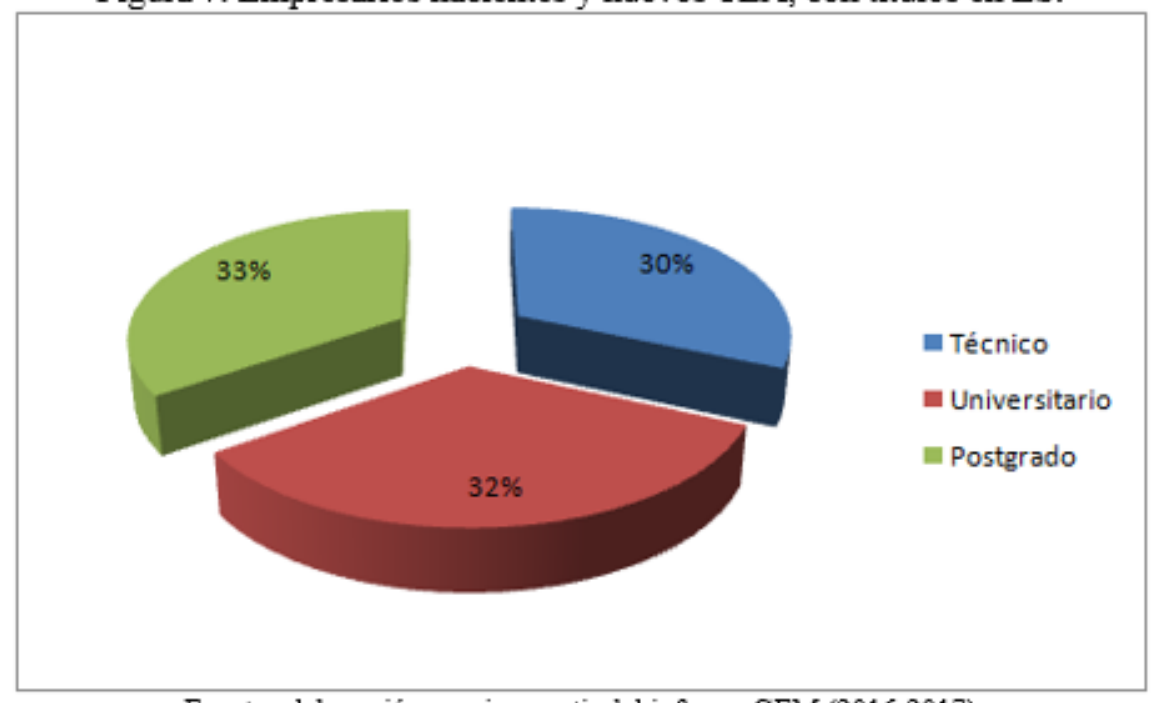

Fuente: elaboración propia a partir del informe GEM (2016-2017)

Para tener en cuenta con respecto a la empleabilidad y emprendimiento, es de resaltar el seguimiento, control y sistematización de la información recolectada anualmente, Colombia ha fomentado el entorno propicio para la formación de alianzas estratégicas entre las universidades y el sector empresarial, muy a pesar de ello se encuentran falencias que dificultan la actividad empresarial como: falta de coherencia en la formación para el emprendimiento en los diferentes niveles educativos, se requiere fortalecer la mentalidad empresarial (riesgo, innovación y creatividad) y fortalecer la solidaridad empresarial en contraposición a la competencia desleal e individualidad; la carga tributaria es elevada lo que ocasiona desmotivación al espíritu empresarial y el exceso de burocracia en las entidades del estado encargadas de liderar y gestionar los programas correspondiente.

Se concluye que para impulsar el progreso del país, es vital que el sector educativo empodere a sus estudiantes hacía el emprendimiento como generador de empleo, riqueza y bienestar o hacía la empleabilidad cualificada que lo convierta en un líder o referente en el campo laboral.

\section{Diacronía de la educación superior}

Al hablar de diacronía de la ES se hace necesario valorar los principios fundamentales, que han servido de marco de reflexión y orientación profesional a la humanidad, para establecer dentro 
de su evolución aquellas características y elementos que a través de los tiempos se han adaptado y movilizado acorde a la globalización e internacionalización, otorgándole un lugar preponderante dentro de la comunidad mundial como eje articulador del desarrollo sostenible y el progreso de la sociedad a través del conocimiento científico.

Los fundamentos tradicionales de la ES trazaron la ruta de la educación regional y local, toda vez que los directivos y catedráticos se orientaron por la autonomía, la libertad de cátedra, la investigación, la producción científica de los estudiantes, la formación para el trabajo y la evaluación (López, 2008). Estos principios se mantienen, porque independientemente del tiempo todo estudiante universitario recibe la formación necesaria para producir conocimiento, proyección profesional hacía el sector laboral y los profesores mantienen independencia en la construcción de sus planes y programas al servicio de la comunidad estudiantil, los procesos de evaluación han cambiado de acuerdo a los procesos de acreditación y registro.

Con el paso del tiempo, paulatinamente la educación se vio permeada por elementos y aspectos de la sociedad globalizada, que generaron cambios de paradigma y nueva visión de la ES, como son: la diversificación, el uso de las TIC, la inclusión de la virtualidad, la conformación de redes de conocimiento y la investigación focalizada. La inmersión de estos elementos genera cambios positivos y estructurales en la ES, expresados tanto en la normatividad mundial y regional, como en la cotidianidad del colectivo universitario. La declaración de Incheon, educación 2030 (UNESCO, 2015) marca un hito en la nueva visión de la ES, hace énfasis en una formación humanista, regida por principios de equidad, inclusión y justicia social para todos y a lo largo de toda la vida; a partir de esta declaración la ES se enriquece con el refuerzo de concepciones como: holística, pertinente, humanista, integradora, intercultural, inclusiva, equitativa y resiliente; a la par surgen nuevas recomendaciones para lograr cumplir las metas propuestas en pro del progreso y el bienestar de los pueblos, para nombrar algunas tenemos: establecimiento de sistemas de registro, acreditación, homologación, movilidad; sistemas de aseguramiento de la calidad, acceso, permanencia, graduación; procesos de inspección y vigilancia; financiamiento y rendición de cuentas; índices de inclusión, sostenibilidad y enseñanza para la ciudadanía mundial. En la figura 4 se ilustra la evolución de la ES. 
Figura 4: Diacronía de la ES.

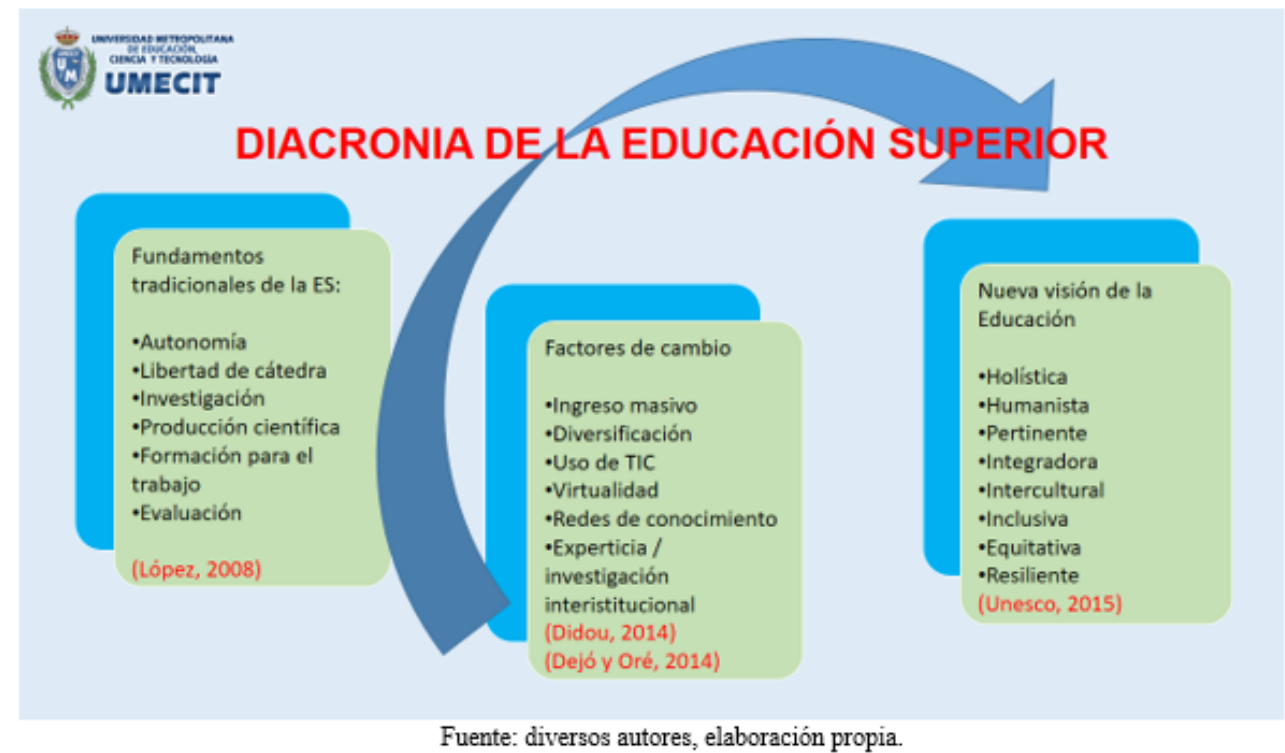

Es necesario que la sociedad y especialmente los agentes educativos se comprometan en innovar, actualizarse y en algunos casos transformarse teniendo en cuenta los nuevos lineamientos mundiales para ajustarse a esa nueva mirada holística y humanista que contribuya al desarrollo sostenible de los pueblos.

\section{Responsabilidad social euleriana de las ES, las 3E}

Para finalizar es importante retomar el concepto de educación y relacionarlo dentro de un esquema euleriano con las tres macrotendencias seleccionadas, de las tomadas al inicio del presente ejercicio de reflexión, que se consideran las más amplias y visionarias de la educación, como son: la educabilidad, el emprendimiento y la empleabilidad, que reflejan el objeto mismo de la ES en la actualidad, en otras palabras: las 3E. Según Barrera (2014), la educación es un proceso euleriano de creación de conocimiento que consiste en la integración de los diferentes saberes que se van presentando durante todo el proceso educativo, hasta conformar un corpus conceptual, un corpus decisorio, que potencie el sentido de lo aprendido y se manifieste cada vez con una mayor complejidad intelectual y de conocimiento. En la figura 5 se presenta el correspondiente esquema euleriano. 
Figura 5. Responsabilidad social euleriana de las ES, las 3E

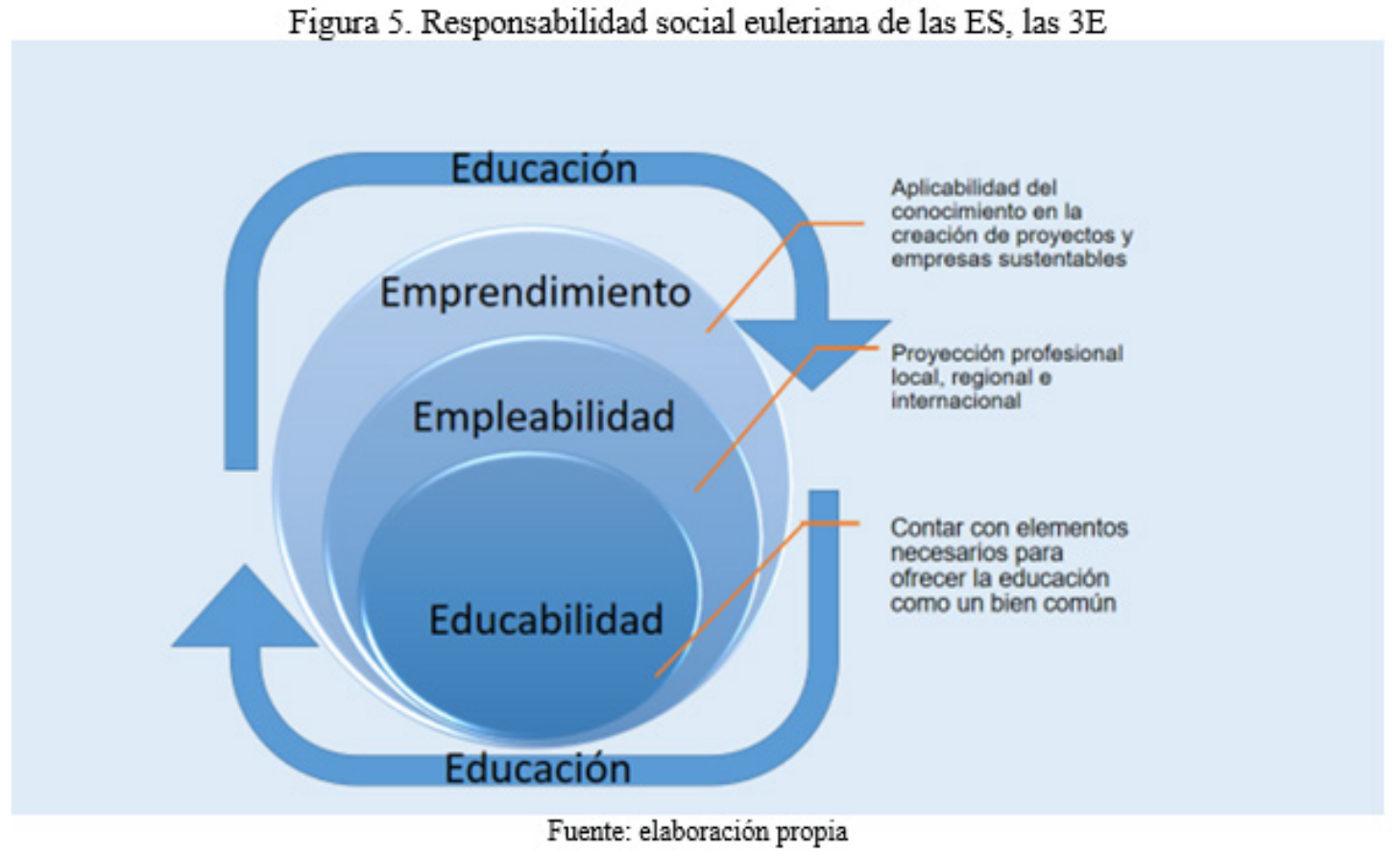

La misión de todo agente educativo es propender por una educación de calidad teniendo como guía y fundamentos los lineamientos expuestos por la normatividad a nivel mundial, regional y local, esto implica que los profesionales de la educación, en este caso se hace referencia a los licenciados, especialistas, magísteres y doctores en educación, deben aportar desde su contexto laboral, profesional y social con procesos investigativos consistentes, permanentes y dinámicos a enriquecer los procesos administrativos, pedagógicos y ambientales, toda vez que la educabilidad hace referencia a la consecución de los elementos necesarios para surtir de eficacia y eficiencia el acto educativo- formativo. De igual forma la sociedad global ha pasado por una serie de cambios y adaptaciones, donde el perfil del egresado de la ES va más allá de obtener un título profesional, se centra en la posibilidad de acceder a un empleo acorde a sus competencias, lo que implica que desde el nicho de las instituciones, los profesores y dirigentes educativos implementen unas políticas, didácticas y estrategias que potencialicen su quehacer en el contexto laboral; pero, la evolución del concepto de formación educativa, se ha transformado hasta tener como intención clara y notoria ofrecer egresados emprendedores, empoderados de su inquietud investigativa y productiva, que los lleve a generar empresa y empleo, tarea aún más profunda para los actores y entidades gubernamentales, nacionales e internacionales, porque requiere hacer una amalgama de elementos como; inclusión, calidad, pertinencia, equidad, investigación, interculturalismo, solidaridad, sostenibilidad e internacionalización. Como se aprecia la meta es generar las 3E: educabilidad, empleabilidad y emprendimiento, como pilares de la Responsabilidad Social Euleriana de las ES. 


\section{Reflexiones finales}

La comunidad mundial representada por la UNESCO, reconoce en la educación el factor primordial para el desarrollo de los pueblos, en razón a esto ha establecido una agenda a nivel internacional ambiciosa, visionaria y humanista, para la cual se establecieron metas y estrategias que requieren del compromiso constante y el concurso de los dirigentes de todos los países participantes. Con la finalidad de direccionar y gestionar estas políticas internacionales y nacionales, el gobierno colombiano ha creado variados sistemas para su gestión, pero esto ha ocasionado el crecimiento de la burocracia que genera procedimientos y trámites complejos, aumento de costos y falta de cohesión y efectividad en los programas y estrategias que aunado a la falta de recursos se ha diluido su efectividad. De otra parte, las Instituciones de Educación Superior tiene la misión de formar seres humanos competentes académica y profesionalmente, con responsabilidad social, lo cual implica que dentro de la vida institucional se fortalezcan principios deontológicos que trasciendan en la construcción de una sociedad humanizante y sostenible, apoyada en procesos trasdiciplinares.

Dentro de la eulerización de la responsabilidad social de la ES, se encuentra en primera instancia la educabilidad, en torno a la cual giran elementos como: la inclusión, la cobertura, la accesibilidad, la permanencia, la promoción y la calidad. El segundo componente de este proceso, es la empleabilidad, como la responsabilidad social de la ES, la cual convoca: financiamiento, humanismo, movilidad, sistemas de registro y acreditación, oferta y demanda laboral, competencias y profesionalización. En la escala más elevada, se ubica el emprendimiento, como la relación directa entre educación, economía y productividad, que generan riqueza, bienestar y empleo, impulsadores del desarrollo, en la cual se hace presente la internacionalización, interculturalismo y sostenibilidad. Es el momento propicio para invitar a otros profesionales en educación a repensar, replantear y complementar este proceso de eulerización de la ES.

De igual manera, es necesario desde el contexto dar respuestas integrales a los grandes desafíos sociales, económicos y ambientales, lo que implica traspasar barreras y límites, crear asociaciones, alianzas, redes de apoyo y cualquier otro tipo de organizaciones eficaces para lograr alcanzar las metas en educación, que aporten al mundo dignidad humana, inclusión social y protección del medio ambiente, crecimiento económico equitativo, ciudadanos ejemplares, comprometidos, competentes y capaces de construir un mundo más seguro, ecológico, sano y más justo para todos. ¡Se vale soñar! 


\section{Referentes}

Barrera Morales Marcos Fidel. Blog Abstracción. (2013).¿Qué es la Holología? Recuperado de: https://marfibamo.blogspot.com.co/2013/12/que-es-la-hologogia.html

Barreras Morales Marcos Fidel. BlogAbstracción. (2014). Recuperado de: https://marfibamo. blogspot.com.co/search?q=semasiologia

CECODES. (2015). Recuperado de: http://www.cecodes.org.co/site/quienes-somos/

COLCIENCIAS. (2017). Boletín Estadístico Número 5. Recuperado de: http://www. colciencias.gov.co/sites/default/files/boletin-estadistico-2017.pdf

COLCIENCIAS. (2018). Recuperado de: http://colciencias.gov.co/la-ciencia-en-cifras/ presupuesto-colciencias. Constitución Política de Colombia (1886). Recuperado de: http:// es.presidencia.gov.co/normativa/constitucion-politica

Constitución Política de Colombia(1991). Recuperado de: http://es.presidencia.gov.co/ normativa/constitucion-politica

Consejo Nacional de Educación Superior, CESU. (2014). Acuerdo por lo superior 2034. Propuesta de política pública por la excelencia de la educación superior en Colombia en el escenario de la paz. Recuperado de: http://www.dialogoeducacionsuperior.edu.co/1750/ articles-319917_recurso_1.pdf

Dejo J Y Oré B. (2014). La educación superior en el siglo XXI: ¿son nuevos los retos?. En blanco y negro, Vol. $5 \mathrm{~N}^{\circ}$ 2. Recuperado de: http://revistas.pucp.edu.pe/index.php/ enblancoynegro/article/view/11384/11897

Departamento Administrativo Nacional de Estadística. DANE. (2018). Recuperado de: https://censo2018.dane.gov.co/

Didou S. (2014).La UNESCO y la educación superior, 2014-2017: aportes de la Reunión de Cátedras UNESCO sobre la educación superior, las TIC en la educación y los profesores. Recuperado de: http://www.unesco.org/new/fileadmin/MULTIMEDIA/HQ/ED/pdf/ UNESCO-summary-report-chairs-2014-1.pdf

ICETEX. (1998). Recuperado de: https://portal.icetex.gov.co/Portal/Home/estudia-encolombia/sistema-educativo-en-colombia/

Observatorio Laboral para la Educación. (2018). Seguimiento a graduados. Recuperado de: http://www.graduadoscolombia.edu.co/html/1732/w3-article-346742.html 
García Cediel Gustavo, Gómez Núñez Liyis, Pereira Fernando, Moreno Jhon , Varela, Rodrigo, Buelvas Piedad, Franco Camila, López Saray Matiz, Francisco. (2017). Actividad Empresarial Colombiana. Reporte GEM Colombia 2016/2017. Recuperado de: https:/www. researchgate.net/publication/317929591_Actividad_Empresarial_Colombiana_Reporte_ GEM_Colombia_20162017

Ley 1014. (2006). Ley de Emprendimiento en Colombia. Recuperado de: https://www. google.com/h?q=ley+de+emprendimiento + en + colombia + pdf\&sa $=$ X\&ved=0ahUKEwi73Z KzlJrbAhVQoFMKHZxKDv0Q1QIIxQEoAg\&biw=1366\&bih=662

López Segrera F. (2008). Tendencias de la educación superior en El mundo y en América Latina y el Caribe. Recuperado de: http://www.scielo.br/pdf/aval/v13n2/03.pdf

Ministerio de Educación Nacional. Colombia. (1992). Ley 30 por la cual se organiza el servicio público de la Educación Superior. Recuperado de: https://www.cna.gov.co/1741/ articles-186370_ley_3092.pdf

Ministerio de Educación Nacional. MEN. (2013). Lineamientos de la política de educación superior inclusiva. Recuperado de: https:/www.mineducacion.gov.co/1759/articles-357277_ recurso.pdf

Ministerio de Educación Nacional. MEN (2017). Resolución 20797 del 09 de octubre de 2017. Recuperado de: https://www.mineducacion.gov.co/1759/articles-363182_archivo_ pdf.pdf

Ministerio de Educación Nacional. MEN. (2018). Convenios internacionales. Recuperado de: https:/www.fumgeront.com/images/pdf/otros_textos/GERONTO_CONVENIOS_ INTERNACIONALES_DE_COLOMBIA_CON_OTROS_PAISES.pdf

Ministerio de Educación Nacional. MEN- SINIES (2018). Recuperado de: https://www. mineducacion.gov.co/sistemasinfo/snies/

Ministerio de Tecnologías de la Información y Comunicaciones. Min TIC. Recuperado de: http://www.mintic.gov.co/portal/vivedigital/612/w3-propertyvalue-7240.html

UNESCO. (1990). Declaración mundial sobre educación para todos y marco de acción para satisfacer las necesidades básicas de aprendizaje.Jomten, Tailandia. Recuperado de: http:// www.unesco.org/education/pdf/JOMTIE_S.PDF

UNESCO. (1998). Conferencia Mundial sobre la Educación Superior para el siglo XXI. Recuperado de: http://www.unesco.org/education/educprog/wche/declaration_spa.htm 